\title{
Performed Product Investigation Result Evaluation Conclusion Code
}

National Cancer Institute

\section{Source}

National Cancer Institute. Performed Product Investigation Result Evaluation Conclusion

Code. NCI Thesaurus. Code C93958.

A coded value specifying the relevant fact within the context of the evaluation final results for a reported suspect medical device. 